\title{
Impairment of Tongue Control During Bolus Hold
}

National Cancer Institute

\section{Source}

National Cancer Institute. Impairment of Tongue Control During Bolus Hold. NCI

Thesaurus. Code C127189.

An observation of an individual's tongue control during bolus hold. 